\title{
Simple and rapid method for silver nanoparticles incorporation in polymethyl methacrylate (PMMA) substrates
}

\author{
V. Campos, I. DeAlba-Montero, Facundo Ruiz \\ Facultad de Ciencias, Universidad Autónoma de San Luis Potosí, \\ San Luis Potosí, SLP, 78295 México \\ C. Butrón-Téllez Girón*, E. García-García \\ Facultad de Estomatología, Universidad Autónoma San Luis Potosí, \\ San Luis Potosí, SLP, 78290 México \\ M. Loredo-Tovías \\ Facultad de Ingeniería, Universidad Autónoma de San Luis Potosí, \\ San Luis Potosí, SLP, 78210 México \\ (Received: July 8th, 2017; Accepted: November 17th, 2017)
}

\begin{abstract}
Due to its antimicrobial properties, silver has been used in many areas of medicine and today silver nanoparticles have been incorporated into different biomaterials. The objective of this study was to implement a simple method for the incorporation of silver nanoparticles in polymethyl methacrylate substrates, to determine their mechanical properties, antimicrobial functionality and the solubility of silver incorporated. Using this approach an antimicrobial material can be obtained; the surface of a commercial polymethyl methacrylate (Opti-cryl@) was impregnated with silver nanoparticles (AgNps) using a spray deposition method $(0.03 \%$ by weight $)$. The antimicrobial activity of the material was evaluated using the Japanese industrial standard (JIS Z 2801) against Escherichia coli and Staphylococcus aureus. Inductively coupled plasma optical spectrometry (ICP-OES) was used to measure the solubility of the incorporated silver nanoparticles. Mechanical tests of flexural strength were performed to observe changes in mechanical properties. The antimicrobial results show that PMMA / AgNps has significant antimicrobial activity, showing better results for Escherichia coli. ICP-OES analysis suggests low solubility in silver nanoparticles. Mechanical tests showed a 1.6\% increase in flexural strength for PMMA added with silver nanoparticles. The method presented for incorporating silver nanoparticles into PMMA and producing an acrylic antimicrobial substrate is easy and has the advantage of improving its mechanical properties.
\end{abstract}

\section{Introduction}

Due to its antimicrobial properties, particularly against Gram-positive and negative bacteria, silver nanoparticles are good candidates to be used in different areas of medicine and odontology [1]. The application of AgNps in medicine and dentistry materials has been encouraged due to they exhibit a broad-spectrum antimicrobial effect and because they do not lead to the development of resistant bacterial strain [2]. For that reason, they are been widely studied in medical areas, such as in wound sutures, endotracheal tubes, surgical instruments and bone prosthesis [3]. Many studies have reported their incorporation into dental materials to add antibacterial functionality to these materials [4]. The antimicrobial functionality of dental materials could avoid or decrease their microbial colonization and therefore increase and improve oral health levels and life quality [5]. This fact will open a lot of applications in several areas such as endodontic, dental prosthesis, implantology, and restorative dentistry [3].

On the other hand, in the last years, resin-based restorative materials are among the more used materials in dentistry. Most resin systems used in dentistry are based on methacrylates, particularly methylmethacrylates (MMA) and polymethyl methacrylates (PMMAs). Dental PMMAs are used in dentistry for different purposes such as trial base plates [6], dentures bases and orthodontic devices [7]. Even when this polymer is slightly hydrophobic, its surface shows microbial colonization and biofilm formation [8], due to the increased surface roughness and, generally, inferior fitting interfaces provided by the former [9]. It is well known that one of the primary oral diseases causes is provoked the formation of dental plaque and the adhesion of microorganism to specific surfaces at the human oral cavity [9]. So, in order to use PMMA in dentistry applications, it is very important to avoid or to minimize microbial adhesion and their posterior colonization. For this, it is necessary to add antimicrobial properties to the PMMA material; one possible approach is modify the surface properties of PMMA by incorporating a bactericidal/bacteriostatic agent [10]. Silver nanoparticles offer one of the better alternatives, it has been demonstrated that they function as broad-spectrum antimicrobial agent and do not lead to the development of resistant bacterial strain [2]. Previous results have been reported were authors prepare and evaluate a PMMA/AgNps composites using different approaches [11-13]. The aim of this study was to incorporate silver nanoparticles on the surface of a PMMA (Opti-cryl囚) substrate by using a spray method and to evaluate the antimicrobial effectiveness, mechanical properties, and solubility of silver of the final material. Minimum inhibitory concentration of the AgNps used in this work was determined to validate their 


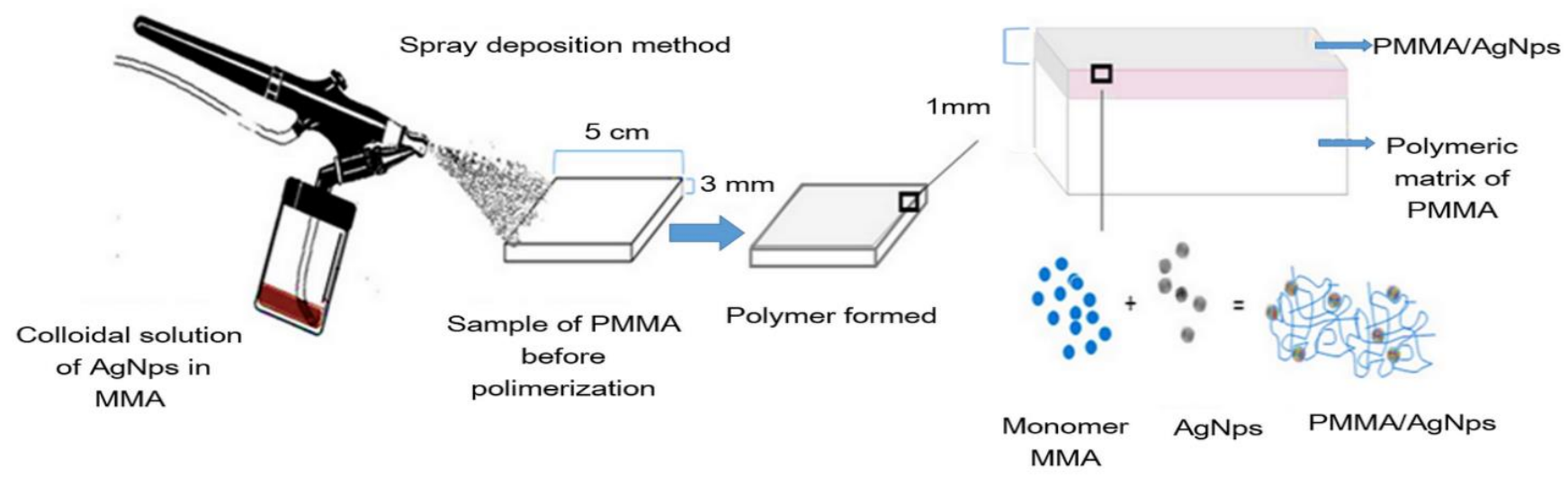

Figure 1. Preparation of the PMMA slabs by spraying deposition method.

antimicrobial activity. MTT (3-(4,5-dimethylthiazol-2-yl)2,5-diphenyltetrazolium bromide) tetrazolium reduction assay was also done for measuring the results of bacterial proliferation.

\section{Experimental details}

\section{Synthesis and characterization of AgNps}

Silver nanoparticles (AgNps) were synthesized by using a chemical reduction method in an aqueous solution according to Martínez-Castañon et al [14]. The colloidal dispersion was characterized with Transmission Electron Microscopy (JEOL JEM-1230 a $100 \mathrm{kV}$ ). UV-Vis spectra was recorded to verify the silver presence.

\section{Sample Preparation}

Samples were prepared by coating previously prepared $5 \times 5 \times 0.3 \mathrm{~cm}$ PMMA (Opti-cryl@) plates with an AgNps / MMA solution, the coating solution was sprayed onto the surface of the polymeric substrate as shown in Figure 1. The coating was prepared by mixing silver nanoparticles with MMA monomer using a concentration of $6300 \mathrm{ppm}$ for silver. $400 \mu \mathrm{l}$ of this solution was deposited on the slab surface of PMMA using an airbrush. The average weight of the slabs was $6.6 \mathrm{~g}$ and the total silver content on the surface of the PMMA plate was $2520 \mu \mathrm{g}$; representing $0.038 \%$ by weight and is equivalent to $338 \mathrm{ppm}$.

Minimum inhibitory and bactericide concentration of AgNps Minimum inhibitory concentrations (MIC), leading to the inhibition of bacterial growth (CLSI M100- S25 January 2015), were obtained using the standard microdilution broth method. The strains tested were Escherichia coli (ATCC 8739) and Staphylococcus aureus (ATCC 6538P). The bacterial concentration was standardized to an optical density of 0.2 at $568 \mathrm{~nm}$ (approximately $1 \times 10^{8} \mathrm{CFU} / \mathrm{mL}$ ) using the McFarland scale. The AgNps dispersion were diluted with $50 \mu \mathrm{L}$ of Mueller Hinton broth and $50 \mu \mathrm{L}$ of phosphate buffer inoculated with the tested strains at a concentration of $1 \times 10^{5} \mathrm{CFU} / \mathrm{mL}$ was grown for $24 \mathrm{~h}$ at $35 \pm 1{ }^{\circ} \mathrm{C}[15]$.

\section{MTT Assay}

The MTT assay was used for measuring the proliferation of bacterial cells according to DeAlba-Montero et al. Bacterial cells with a concentration of $10^{5} \mathrm{CFU} / \mathrm{mL}$ were incubated into Mueller-Hinton broth at $50 \mu \mathrm{L}$ per well in 96-well microtiter plates. Threefold serial dilutions of AgNps were added to wells containing bacterial cells. After 24 hours of incubation at $37{ }^{\circ} \mathrm{C}$, each concentration was tested in triplicate. 24 hours later, $10 \mu \mathrm{L}$ of the MTT $(5 \mu \mathrm{L} / \mathrm{mL})$ reagent was added to each well and the plates were incubated for $4 \mathrm{~h}$ at $37^{\circ} \mathrm{C}$. Then, DMSO $(100 \mu \mathrm{L})$ was added to finish the reaction; the plate was shaken gently to redissolve the crystals formed. The absorbance was read at $490 \mathrm{~nm}$ wavelength by a Microplate Reader (Bio-Rad Laboratories) spectrophotometer. The results were expressed as the inhibition ratio of cell increase calculated as $[(\mathrm{A}-\mathrm{B}) / \mathrm{A}] \times 100 \%$, in which $\mathrm{A}$ and $\mathrm{B}$ represent the average of live bacteria of the control and samples, respectively [16].

\section{Antibacterial surface activity}

For the antimicrobial evaluation of the samples surfaces was used the Japanese industrial standard JIS Z 2801-2010, Antibacterial products test for antibacterial activity and efficacy [17]. The samples were divided into four groups: group A: PPMA (Opti-cryl®)/AgNps; group B: PMMA (Opti-cryl®); C: Glass as a positive control; D: Copper as a negative control. All samples were prepared on $5 \times 5 \times 0.3 \mathrm{~cm}$ slabs, for the PMMA with/without AgNps an A-silicon guide (Variotime HERAEUS) was used and the material was handled in accordance with the manufacturer's specifications. Test pieces of PMMA (with and without AgNps), ordinary glass, and copper were inoculated with the strains Escherichia coli ATCC 8739 and Staphylococcus aureus ATCC 6538P for the antimicrobial tests. Each test was performed in triplicate as described by the JIS Z 2801.

\section{Silver release quantification}

An Inducted coupled plasma- optical emission spectrophotometer (ICP-OES, Thermo Fisher Scientific, iCAP 7000), was used to measure the solubility of silver of the PMMA acrylic added with AgNps. Six samples of 
$5 \times 5 \mathrm{~cm}$ were immersed in $50 \mathrm{~mL}$ of deionized water and incubated at $37 \pm 1{ }^{\circ} \mathrm{C}$ for 48 hours and 8 days respectively. The ICP-OES measurement was made by triplicate and the average and standard deviation were calculated for each sample.

\section{Mechanical tests}

The flexural strength of the samples PMMA/AgNps and the neat PMMA was calculated in a universal mechanical testing machine (Shimadzu AGI). For this tests, samples $(3 \times 4 \times 0.5 \mathrm{~cm})$ were kept in deionized water for 48 hours and 8 days at $37 \pm 1{ }^{\circ} \mathrm{C}$ according to ANSI/ADA No. 139, standard for dental base polymers [18].

\section{Statistical analysis}

All experimental treatments were replicated 3 to 6 times. The histogram was generated by Origin 8.0 (Originlab) and line charts by GraphPad Prism 7. T-test and ANOVA were used to determine the $\mathrm{P}$ values. $\mathrm{P}$-value $<0.05$ was considered to be statistically significant.

\section{Results and discussion}

Synthesis and characterization of AgNps

Figure 2 shows an image of Transmission Electron Microscopy (TEM) of synthesized AgNps, in the image it is possible to appreciate that they have an irregular and quasispherical shape. The particle size ranges from 2 to $15 \mathrm{~nm}$.

The UV-Vis absorption spectrum is presented in Figure 3, a curve with a peak at $400 \mathrm{~nm}$ confirms the presence of AgNps.

Table 1 shows the Minimum Inhibitory Concentrations of AgNps against Escherichia coli ATCC 8739 and Staphylococcus aureus ATCC 6538P, compared to
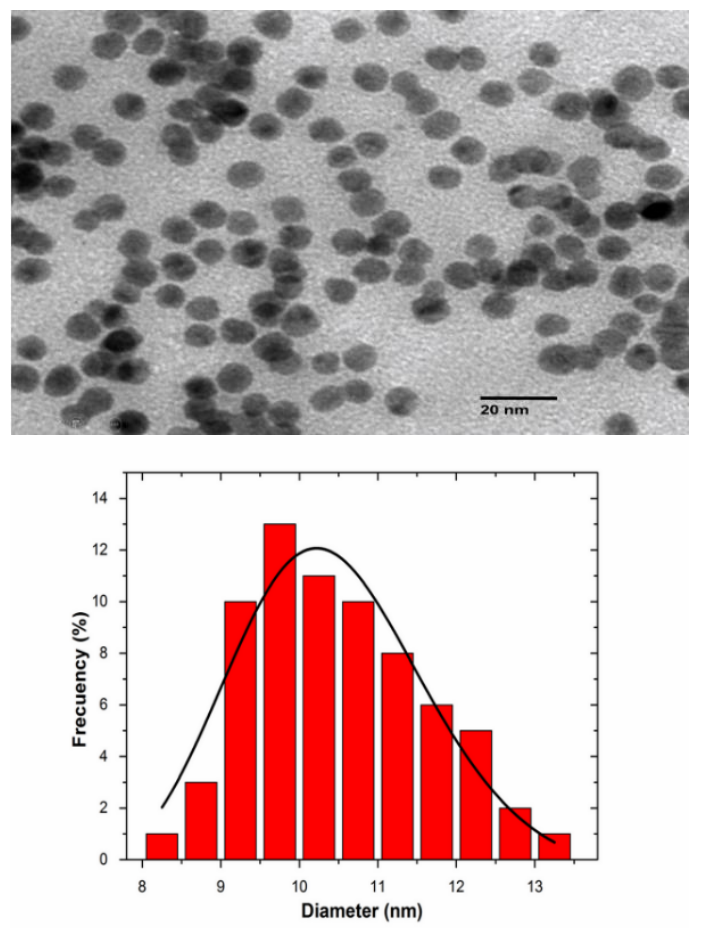

Figure 2. TEM image of the synthetized silver nanoparticles.
Table 1. Minimum inhibitory concentrations.

\begin{tabular}{ccc}
\hline & \multicolumn{1}{c}{$\begin{array}{c}\text { Minimum Inhibitory Concentrations } \\
(\mu \mathrm{g} / \mathrm{mL} \pm \mathrm{SD})\end{array}$} \\
\cline { 2 - 3 } Sample & $\begin{array}{c}\text { Escherichia coli } \\
(\mathrm{ATCC} 8739)\end{array}$ & $\begin{array}{c}\text { Staphylococcus } \\
\text { aureus } \\
(\text { ATCC } 6538 \mathrm{P})\end{array}$ \\
\hline AgNps & $6.74 \pm 0.0$ & $13.48 \pm 0.0$ \\
Amikacin & $16 \pm 0.0$ & $8 \pm 0.0$ \\
Gallic acid & $-{ }^{\mathrm{a}}$ & $-{ }^{\mathrm{a}}$ \\
\hline No antibacterial activity was found with the concentrations used in this
\end{tabular}
a No ant
work

Amikacin, a very well-known antibiotic used for a number of bacterial infections [19], as control negative. It also included the MIC results obtained for the gallic acid, since this compound is the one used in this work as reducing agent to synthetize silver nanoparticles and some reports mention it has some antimicrobial activity [14]. For MIC of AgNps the results obtained from silver nanoparticles were $8.1 \pm 6.6 \mu \mathrm{g} / \mathrm{mL}$ and $5.7 \pm 2.0 \mu \mathrm{g} / \mathrm{mL}$ respectively, in concordance with the parameters obtained for this synthesis $[14,20]$.

In Figure 4, it can be seen the results of the MTT assay for AgNps. At concentrations of 1.68 and $3.37 \mu \mathrm{g} / \mathrm{ml}$ the percentage of viability is high; at the concentration of $6.74 \mu \mathrm{g} / \mathrm{mL}$ the viability value decreases drastically for the case of Escherichia coli whereas for Staphylococcus aureus the percentage remains high; at concentrations of $13.48 \mu \mathrm{g} / \mathrm{mL}$ and higher values, the percentage begins to decrease in both microorganisms. These results coincide with previously obtained MIC values (Table 1).

\section{Antibacterial surface activity}

Figure 5 shows the Log reduction results obtained using the JIS Z 2801-2010. As we can see values the antimicrobial activity of the PMMA/AgNps samples against both strains were similar to the copper samples (negative control), for PMMA/AgNps the R values were 1.89 (Staphylococcus aureus) and 3.33 (Escherichia coli) that correspond to CFUs reductions in $99 \%$ and $99.9 \%$, respectively. This is a good result for the PMMA acrylic. For the Staphylococcus aureus glass showed no activity at all.

\section{Silver release quantification}

The solubility values of silver on the sample (PMMA/AgNps), in aqueous medium, were obtained through ICP-OES. For the first set of samples $(48 \mathrm{hrs})$ the

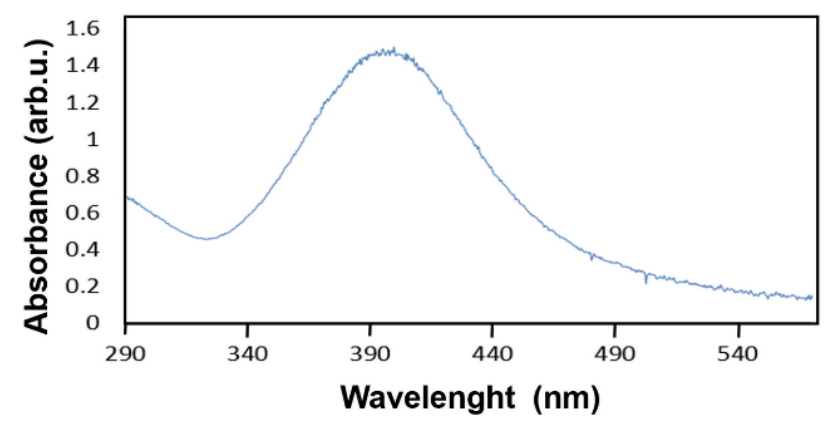

Figure 3. UV-Vis absorption spectra of PMMA/AgNps. 


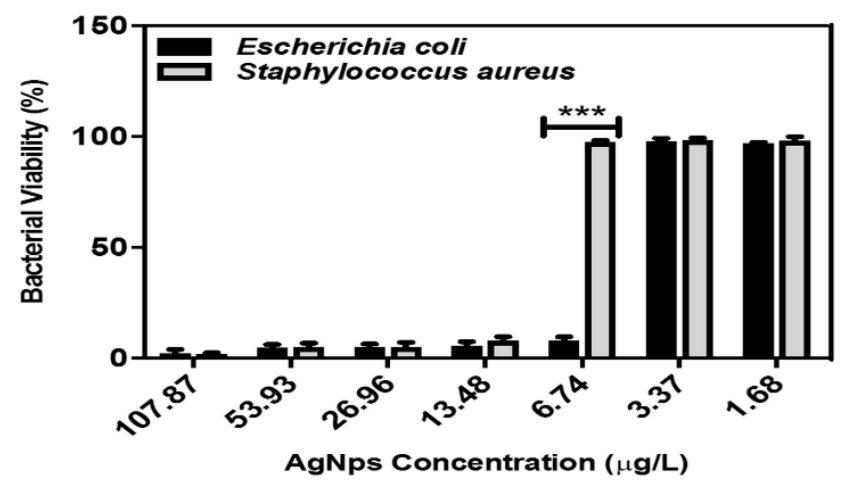

Figure 4. Effect of AgNps on MTT-formazan production during interaction with Escherichia coli and Staphylococcus aureus. Each value represents the mean of 3 replicates.

maximum release value was $0.69 \mathrm{ppm}(\mathrm{mg} / \mathrm{L})$ and the minimum was $0.11 \mathrm{ppm}$, the average value was $0.42 \mathrm{ppm}$ with a standard deviation (STD) of $0.26 \mathrm{ppm}$. For the set of samples incubated at 8 days, the maximum release value was $0.95 \mathrm{ppm}$ and the minimum was $0.23 \mathrm{ppm}$ the average value was $0.48 \mathrm{ppm}$ with a STD of $0.32 \mathrm{ppm}$.

According to these results, silver is released from the PMMA matrix as much as a $1.19 \%$ for the set of samples incubated for $48 \mathrm{hrs}$ and $1.81 \%$ for the 8 days case. The difference in the release values of silver it be related to the amount of AgNps impregnated on the polymer surface from samples in the same set. On the other hand, it seems that most of the released silver is released in the first $48 \mathrm{hrs}$, as can be inferred from the small difference between releasing values between both set of samples. There is no evidence to know if silver is released in form of nanoparticle or in ionic form since ICP-OES reports the total amount of silver released. Nevertheless, probably silver is released mainly in form of nanoparticles due to the medium conditions.

\section{Mechanical tests}

Table 2 shows the flexural strength of the PMMA/AgNps $(69.02 \pm 6.14 \mathrm{MPa})$ compared to the PMMA without AgNps $(67.89 \pm 8.54 \mathrm{MPa})$, an increase of $1.6 \%$ was observed for the PMMA added with AgNps.

Using two different assays, and before being incorporated to the surface of a PMMA matrix, the antimicrobial activity of the silver nanoparticles synthesized in this work was validated. The results coincide with others previously reported. Even though the antibacterial mechanism of silver has not been yet clarified [21,22], is known that silver ions are the biocidal species. From the results of this work, there is no further evidence to confirm this fact. However, we reported an AgNps/PMMA material with very efficient antimicrobial functionality, where the antimicrobial property

Table 2. Flexural strength.

\begin{tabular}{cc}
\hline Sample & Flexural strength \\
\hline PMMA/AgNps & $69.02 \pm 6.14$ \\
PMMA & $67.89 \pm 8.54$ \\
ANSI/ADA & $\geq 60$ \\
No.139 & \\
\hline
\end{tabular}

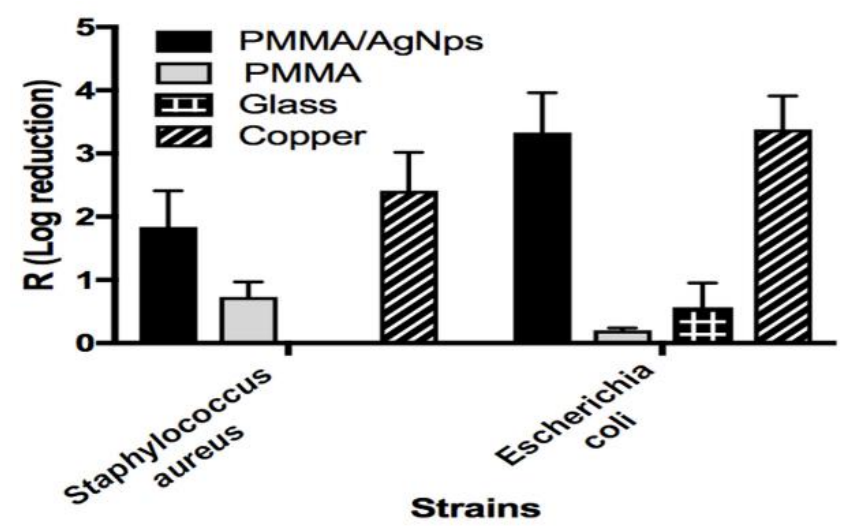

Figure 5. $R$ (Log reduction) of viable cells obtained with JIS Z 2801 test shows the antimicrobial activity of the PMMA/AgNps.

added to the acrylic material corresponds to the incorporated silver nanoparticles. [23]. Several studies have evidenced that silver clusters embedded in polymeric systems, are weakly attached to the main polymeric chains, therefore are able to release silver ions and nanoparticles due to water absorption of the polymeric matrix [24]. In the present investigation, the results of silver solubility were below the reported values for others studies related cytotoxicity, inflammation, and genotoxicity [25]. The mechanical tests of the nanocomposite AgNps/PMMA (flexural strength) evidence that the incorporation of AgNps does not alter the use and manipulation of the base product of PMMA (Opticryl $($ ), which can be due to the low amount of silver added $(0.03 \mathrm{wt} \%)$.

The results of our study indicate that the use of the spray method to incorporate AgNps to the surface of a PMMA matrix is quite simple and effective, silver remaining attached on the surface of the polymeric matrix, which is the main contact area, and therefore nanoparticles can act as superficial antimicrobial agents. Additionally, the material improve significantly its mechanical properties as consequence of the nanoparticle presence.

\section{Conclusions}

The spray deposition method we present allows an easy incorporation of the AgNps on the surface of the polymeric matrix of the PMMA. The incorporated nanoparticles remain attached, according to our results, to the surface of the polymeric matrix, adding antibacterial functionality, and improving the mechanical properties. The silver release values we found are a quite low and are below to values reported for others studies related to cytotoxicity, inflammation, and genotoxicity.

\section{Acknowledgements}

This study was supported by the Consejo Nacional de Ciencia y Tecnología (CONACYT) and the Doctorado Institucional en Ingeniería y Ciencias de Materiales (DICIM) of the Universidad Autónoma de San Luis Potosí. V. Campos and I. DeAlba-Montero would like to thank CONACYT for Scholarships 234478 and 358436, respectively. 


\section{References}

[1]. R.P. Allaker, J. Dent. Res. 89, 1175 (2010).

[2]. K. Zhang, L. Cheng, S. Imazato, J.M. Antonucci, N.J. Lin, S. Lin-Gibson, Y. Bai, H.H. Xu, J. Dent. 41, 464 (2013).

[3]. J.M. Corrêa, M. Mori, H.L. Sanches, A.D. da Cruz, E. Jr. Poiate, I.A. Poiate, Int. J. Biomater. 2015, 485275 (2015).

[4]. P.C. Siqueira, A.P. Magalhães, W.C. Pires, F.C. Pereira, E.P. Silveira-Lacerda, M.S. Carrião, A.F. Bakuzis, C.A. Souza-Costa, L.G. Lopes, C. Estrela, Clin. Exp. Dent. 7, e622 (2015).

[5]. S. Eckhardt, P.S. Brunetto, J. Gagnon, M. Priebe, B. Giese, K.M. Fromm, Chem. Rev. 113, 4708 (2013).

[6]. T. Ghaffari, F. Hamedirad, B. Ezzati, J. Dent. Res. Dent. Clin. Dent. Prospects 8, 204 (2014).

[7]. R. Gautam, R.D. Singh, V.P. Sharma, R. Siddhartha, P. Chand, R. Kumar, J. Biomed. Mater. Res. B Appl. Biomater. 100, 1444 (2012).

[8]. O. Bazaka, K. Bazaka, in: Biomaterials and Medical DeviceAssociated Infections, Ed. L. Barnes, I. Cooper (Elsevier 2015) pp. 109-132.

[9]. L.C. Dantas, J.P. da Silva-Neto, T.S. Dantas, L.Z. Naves, F.D. das Neves, A.S. da Mota, Int. J. Dent. 2016, 8685796 (2016).

[10]. D. Pavithra, M. Doble, Biomed. Mater. 3, 034003 (2008).

[11]. A. Kotlyar, N Perkas, G. Amiryan, M. Meyer, W. Zimmermann, A. Gedanken, J. Appl. Polym. Sci. 104, 2868 (2007).

[12]. E.H. Alsharaeh, Materials 9, 458 (2016).

[13]. G. Sahal, B. Nasseri, I.S. Bilkay, E. Piskin, J. Appl. Biomater. Funct. Mater. 13, (2015).

[14]. G.A. Martinez-Castañón, N. Nino-Martinez, F. MartinezGutierrez, J.R. Martinez-Mendoza, F. Ruiz, J Nanopart Res. 10, $\underline{1343(2008)}$.
[15]. J.B. Patel, Performance Standards for Antimicrobial Susceptibility Testing: Twenty-fifth Informational Supplement M100-S25 (Clinical and Laboratory Standards Institute. Wayne, PA, USA, 2015).

[16]. I. DeAlba-Montero, J. Guajardo-Pacheco, E. MoralesSánchez, R. Araujo-Martínez, G.M. Loredo-Becerra, G.A. Martínez-Castañón, M.E. Compeán-Jasso, Bioinorg. Chem. Appl. 2017, 1064918 (2017).

[17]. JIS Z 2801: Antibacterial products - Test for antibacterial activity and efficacy (Japanese Industrial Standards, 2010).

[18]. Y.W. Cavalcanti, M.M. Bertolini, A.A. Del Bel Cury, W.J. Da Silva, J. Prosthet. Dent. 112, 1539 (2014).

[19]. F. Martinez-Gutierrez, P.L. Olive, A. Banuelos, E. Orrantia, N. Nino, E.M. Sanchez, F. Ruiz, H. Bach, Y. Av-Gay, Nanomedicine 6, 681 (2010).

[20]. J.F. Hernández-Sierra, F. Ruiz, D.C. Cruz Pena, F. MartínezGutiérrez, A.E. Martínez, A. de J. Guillén, H. Tapia-Pérez, G.M. Castañón, Nanomedicine 4, 237 (2008).

[21]. S. Prabhu, E.K. Poulose, Int. Nano Lett. 2, 32 (2012).

[22]. I. Sondi, B. Salopek-Sondi, J. Colloid Interface Sci. 275, 177 (2004).

[23]. A.B. Smetana, K.J. Klabunde, G.R. Marchin, C.M. Sorensen, Langmuir 24, 7457 (2008).

[24]. S. Kittler, C. Greulich, J. Diendorf, M. Köller, M. Epple, Chem. Mater. 22, 4548 (2010).

[25]. M.V. Park, A.M. Neigh, J.P. Vermeulen, L.J. de la Fonteyne, H.W. Verharen, J.J. Briedé, H. van Loveren, W.H. de Jong, Biomaterials 32, 9810 (2011).

(C) 2017 by the authors; licensee SMCTSM, Mexico. This article is an open access article distributed under the terms and conditions of the Creative Commons Attribution license (http://creativecommons.org/licenses/by/4.0/). 